\title{
Refining and Casting of Steel
}

\author{
Karel Gryc ${ }^{1, *}$ and Jan Falkus ${ }^{2}$ (D) \\ 1 Environmental Research Department, Faculty of Technology, Institute of Technology and Business in České \\ Budějovice, Orkužní 517/10, 37001 České Budějovice, Czech Republic \\ 2 Department of Ferrous Metallurgy, Faculty of Metals Engineering and Industrial Computer Science, AGH \\ University of Science and Technology, Mickiewicza Av. 30, 30-059 Kraków, Poland; jfalkus@agh.edu.pl \\ * Correspondence: gryc@mail.vstecb.cz; Tel.: +420-777-18-78-98
}

Received: 1 February 2020; Accepted: 21 February 2020; Published: 24 February 2020

\section{Introduction and Scope}

Steel was the most requested material all over the world during the past fast technically evolving centuries. As our civilization grows and its technological development is connected with more demanding processes, it is more and more challenging to fit required physical and mechanical properties for steel in its huge portfolio of grades for each steel producer. It is necessary to improve the refining and casting processes continuously to meet customer requirements and lower the production costs to remain competitive.

New challenges relating to both the precise design of steel properties and reduction of production costs are combined with paying special attention to environmental protection. These contradictory demands are the theme of this Special Issue.

\section{Contribution to the Special Issue}

The papers covered by this Special Issue are state-of-the-art in the fields of crucial multiphase interactions in the steel making furnaces: basic oxygen furnace (BOF) [1] and electric arc furnace (EAF) [2]. Next, the research focuses on the matters related to the secondary refining processes; fluid's turbulences with nearby metal-slag interface in the ladles [3], the evolution of inclusions for Ti-bearing steels treated by calcium [4], and an influence of aluminum on flux flow in the ladle during Ruhrstahl Heraeus (RH) degassing operations [5]. Other papers are devoted to a geometry of impact area in the tundish [6], cleanliness consequences of an intermixing of the different steel grades in the tundish [7], and the reoxidation of steel from tundish cover flux [8]. Three papers are based on the studies, regarding the processes taking place in the mold from the viewpoint of heat transfer and multiphase flow influenced by deep submerged entry nozzle (SEN) immersion [9], nozzle clogging [10], and mold flux interaction with steel [11]. Finally, the authors contributed to this Special Issue by also focusing their attention on the complex phenomenon connected to steel cooling, its solidification and quality [12-15]. All published contributions and their briefly commented upon abstracts are organized based on the technological flow valid for modern steel production in the next subchapters.

\subsection{Studies of the Slags in Steel-Making Furnaces}

Baricová et al. [1] present the results of their investigation of changes in the chemical and mineralogical composition of slag during steel production in a BOF. This process was monitored using the slag samples that were collected during the period when oxygen blowing into a BOF was interrupted. Besides other findings, the results show that the structure of the slag related to its chemical composition was more significantly affected by the added slag-forming additives. The changes in the slag structure reflected the process of the gradual dissolution of lime in the slag. While in the primary slag, the predominating structure components were $\mathrm{SiO}_{2}$ and lime, after the eighth minute 
of oxygen blowing, their contents significantly decreased and the predominating component was dicalcium silicate. After minute 24 of oxygen blowing, the final structure of the slag was formed, with the major component being tricalcium silicate, containing also dicalcium silicate, RO-phase, and calcium ferrites [1].

Assis et al. [2] investigated phosphorus equilibria between molten $\mathrm{Fe}-\mathrm{P}$ alloys and $\mathrm{CaO}-\mathrm{SiO}_{2}-\mathrm{Al}_{2} \mathrm{O}_{3}-\mathrm{P}_{2} \mathrm{O}_{5}-\mathrm{FeO}-\mathrm{MgO}_{\text {saturated }}$ slags based on the trend of using up to $100 \%$ direct reduced iron (DRI) in the batch. The results indicate that there is a significant decrease in the phosphorus partition coefficient (LP) as alumina in the slag increases. The observed effect of alumina on the phosphorus partition is probably caused by the decrease in the activities of iron oxide and calcium oxide. Finally, an equilibrium correlation for phosphorus partition as a function of slag composition and temperature has been developed. It includes the effect of alumina and silica and is suitable for both oxygen and electric steelmaking-type slags [2].

\subsection{Refining the Steel in Ladles}

There are plenty of methods for how to study the phenomenon occurring during these refining processes. The kinetics of interaction at the metal-slag interface and also the possibility of a slag entrapment are strongly influenced by the character of fluid flow in the ladle. Three-phase interactions (metal-slag-argon) in ladle stirring operations have strong effects on the metal-slag mass transfer processes, Calderón-Hurtado et al. [3]. Specifically, the thickness of the slag controls the fluid turbulence to an extent that, once trespassing a critical thickness, increases of stirring strength no longer affects the flow. To analyze these conditions, a physical model considering the three phases was built to study liquid turbulence in the proximities of the metal-slag interface. A velocity probe placed close to the interface permitted the continuous monitoring and statistical analyses of any turbulence. The slag eye opening was found to be strongly dependent on the stirring conditions, and the mixing times decreased with thin slag thicknesses. Slag entrainment was enhanced with thick slag layers and high flow rates of the gas phase. A multiphase model was developed to simulate these results and was found to be a good agreement between experimental and numerical results [3].

Next, Li et al. [4] investigated the influence of aluminum on the evolution of the inclusion in Ti-bearing steel treated by Ca. Experimental simulations of steelmaking with different amounts of aluminum were achieved in the tube furnace at $1873 \mathrm{~K}$, and field scanning electron microscopy and energy dispersive X-ray spectroscopy (FE-SEM and EDX) were employed to explore the characteristics of the inclusions in Ti-bearing steel during the calcium treatment process. It was found that morphologies, chemical compositions, and the size distribution of the inclusions were obviously different before and after calcium treatment. The calcium addition needed to be carefully considered regarding the mass fraction of aluminum with the purpose of modifying the solid inclusions to liquid phases. The thermodynamic analysis of inclusion formation in the Al-Ti-Ca-O system at $1873 \mathrm{~K}$ was conducted, as well as transformation behaviors of inclusions, including all types of solid inclusions and liquid phases during solidification. The thermodynamic equilibrium calculations are in good agreement with experimental data, which can be used to estimate inclusion formation in Ti-bearing steel [4].

Most of the current high-quality steels are treated under vacuum. Zhang et al. [5] have used adopted particle image velocimetry (PIV) with a 1:4 scaled water model. The results of mixing simulation experiments indicated that the mixing time decreased with the increase of the gas blowing rate. However, with the increase of snorkel immersion depth (SID), the mixing time presented a decreasing rend firstly and then increased. The measurement of flow fields of RH ladle by the PIV system can explain the phenomenon above. According to the characteristics of the flow field in $\mathrm{RH}$ ladle, the flow field can be divided into the mixing layer, the transition layer, and the inactive layer. On the one hand, the stirring powers in the RH ladle and vacuum chamber both increase with a higher gas blowing rate, leading to the decrease of mixing time. On the other hand, when SID increases from $400 \mathrm{~mm}$ to $480 \mathrm{~mm}$, the gas blowing depth increases results in the mixing power, and the mixing time decreases at the beginning. Due to too much molten steel in the vacuum chamber and the expanding 
of the inactive layer in $\mathrm{RH}$ ladle however, the utilization rate of the gas driving force begins to decrease. Therefore, the mixing time starts to increase with the increase of SID [5].

\subsection{Design, Intermix and Reoxidation Issues in the Tundish}

Continuous casting operations start by pouring steel from the ladle to the tundish. Bul'ko et al. [6] reported the geometric modification of the tundish impact point. This paper compares the standard impact pad with the "spheric" spherical impact pad using computational fluid dynamics (CFD) tools and physical modelling. The evaluation criteria are residence time and flow in the tundish at three different casting speeds. Compared to the standard impact pad, based on our measurements of residence time distribution (RTD) curves using the water model, the "spheric" impact pad shortened the minimum residence times at casting speeds of 0.8 and $1.2 \mathrm{~m} \cdot \mathrm{min}^{-1}$, which is on the level of $71 \%$ and $76 \%$ of the standard impact pad times under identical conditions. On the other hand, the "spheric" impact pad produced a $6 \%$ longer residence time than the standard impact at casting speed $1.6 \mathrm{~m} \cdot \mathrm{min}^{-1}$. From a visual comparison of flow in the tundish, we can observe that the "spheric" impact pad produces a better flow pattern than the standard impact pad. It has no tendency to shortcut the flow at lower casting speeds. Moreover, dead zone areas are eliminated using the "spheric" impact pad. We can predict that using this impact pad in practice will have a positive influence on steel cleanliness, due to more dynamic steel flow at the steel-slag interface. Furthermore, the slag "eye" phenomenon can be reduced when the "spheric" impact pad is used, compared to using impact pads with a significant piston flow pattern [6].

Next, the study of authors Bul'ko et al. [7] reflects the fact that modern steel plants today produce a large portfolio of various steel grades, many for end-users demanding high quality. In order to utilize the maximum productivity of the continuous-casting machine, it is sometimes necessary to cast steel grades with different chemical compositions in one sequence. It is important, therefore, to know the possibilities of a specific continuous-casting machine to make the Intermix connections as short as possible. Any interference with established procedures may, however, have a negative impact on the cleanliness of the cast steel. Using physical and numerical simulation tools, it was found that reducing the steel level in the tundish during the exchange of ladles makes it possible to shorten the transition zone. Based on research results [7], it can be concluded that the ultra-low tundish (ULT) practice produces savings in terms of shorter transition zones, thereby increasing steel yields in the continuous-casting process. Under the given conditions, the ULT practice enabled a $20 \%$ shortening of the transition zone. The area of higher inclusion concentration during the ULT practice was located in the transition part of the slab, and therefore, had no negative effect on the final quality of the cast steel [7].

Wang et al. [8] studied aluminum-killed steel's reoxidation by $\mathrm{Cr}_{2} \mathrm{O}_{3}$ from the tundish cover flux. Reoxidation has long been a problem when casting ultra-low oxygen liquid steel. An experimental study of the reoxidation phenomenon caused by $\mathrm{Cr}_{2} \mathrm{O}_{3}$-bearing cover flux of Al-killed steel is presented here. $\mathrm{MgO}-\mathrm{CaO}-\mathrm{SiO}_{2}-\mathrm{Al}_{2} \mathrm{O}_{3}-\mathrm{Cr}_{2} \mathrm{O}_{3}$ tundish cover fluxes with various $\mathrm{Cr}_{2} \mathrm{O}_{3}$ contents were used to study the effects of $\mathrm{Cr}_{2} \mathrm{O}_{3}$ on total oxygen content $(\mathrm{T}[\mathrm{O}])$ and the alumina and silicone loss of Al-killed steel at $1923 \mathrm{~K}\left(1650{ }^{\circ} \mathrm{C}\right)$. It was found that $\mathrm{Cr}_{2} \mathrm{O}_{3}$ can be reduced by $\mathrm{Al}$ to cause reoxidation, and the reaction occurs mainly within two to three min after the addition of the tundish cover flux with $5 \%$ and $10 \% \mathrm{Cr}_{2} \mathrm{O}_{3}$ concentration. $\mathrm{T}[\mathrm{O}]$ and $\mathrm{Al}$ loss increase with higher $\mathrm{Cr}_{2} \mathrm{O}_{3}$ concentration flux. Two controlled experiments were also carried out to investigate the oxygen transported to the steel by the decomposition of $\mathrm{Cr}_{2} \mathrm{O}_{3}$. It was calculated that when $\mathrm{Al}$ is present in steel, more than $90 \%$ of the reoxidation of $\mathrm{Cr}_{2} \mathrm{O}_{3}$ is caused by $\mathrm{Al}$, and the rest is caused by decomposition [8].

\subsection{Multiphase Flow and Multiphase Interactions in the Mould}

The mold is the last steel production node where a liquid steel interacts with its surroundings. The effect of the immersion depth of a new swirling flow tundish SEN (Submerged Entry Nozzle) on the multiphase flow and heat transfer in mold was studied using numerical simulation by Ni et al. [9]. 
The RSM (Reynolds Stress Model) and the VOF (Volume of Fluid) model were used to solve the steel and slag flow phenomena. The results show that SEN immersion depth can significantly influence the steel flow near the meniscus. Specifically, an increase in the SEN immersion depth decreases the interfacial velocity, and this reduces the risk for the slag entrainment. The calculated Weber Number decreases from 0.8 to 0.2 when the SEN immersion depth increases from $15 \mathrm{~cm}$ to $25 \mathrm{~cm}$. With a large SEN immersion depth, the steel flow velocity near the solidification front, which is below the mold level of the SEN outlet, increased. The temperature distribution has a similar distribution characteristic for different SEN immersion depths. The high temperature region is located near the solidification front. The temperature near the meniscus was slightly decreased when the SEN immersion depth was increased, due to an increased steel moving distance from the SEN outlet to the meniscus [9].

To solve the nozzle clogging issue in the continuous casting process of 253MA steel, a method of modifying solid inclusions to liquid phases is proposed by Li et al. [10]. The CALculation of PHAse Diagrams (CALPHAD) technique was employed to predict the liquid region of the $\mathrm{Al}_{2} \mathrm{O}_{3}-\mathrm{SiO}_{2}-\mathrm{Ce}_{2} \mathrm{O}_{3}$ system. Then, a thermodynamic package based on the extracted data during the phase diagram optimization process was developed. This package was then used to compute the appropriate aluminum addition, which was $0.01 \%$ in 253MA steel. The Si-Al alloy was chosen as the deoxidant according to the thermodynamic analysis. The solid inclusions were ultimately modified to liquid phases at $1500{ }^{\circ} \mathrm{C}$, when cerium was added through the equilibrium experiments in a $\mathrm{MoSi}_{2}$ tube furnace [10].

Research related to the interaction of selected mold fluxes with aluminum-TRIP steel grades was conducted by Zhang et al. [11] The composition and property variations of two slags during a slag-steel reaction were analyzed. Accordingly, the crystalline morphologies of slag were discussed and the solid layer lubrication performance was evaluated by Jackson $\alpha$ factors. In addition, a simple kinetics equilibrium model was established to analyze the factors which affected $\mathrm{SiO}_{2}$ consumption. The results revealed that slag-steel reacted rapidly in the first $20 \mathrm{~min}$, resulting in a variation of viscosity and the melting temperature of slags. The slag-steel reaction also affected the crystal morphology significantly. Slag was precipitated as crystals with a higher melting temperature, a higher Jackson $\alpha$ factor, and a rougher boundary with the consumption of $\mathrm{SiO}_{2}$ and the generation of $\mathrm{Al}_{2} \mathrm{O}_{3}$. In other words, although generated $\mathrm{Al}_{2} \mathrm{O}_{3}$ acted as a network modifier to decrease the viscosity of the liquid slag layer adjacent slab shell, the consumption of $\mathrm{SiO}_{2}$ led to the deterioration of the lubrication performance in the solid slag layer adjacent copper, which was detrimental to the quality control for high Al-TRIP steel. Finally, a kinetics equilibrium model indicated that it is possible to reduce a slag-steel reaction by adjusting factors, such as the diffusion coefficient $\mathrm{k}, \mathrm{c}_{\mathrm{SiO} 2}, \rho_{\mathrm{f}}$ and $\mathrm{L}_{\mathrm{f}}$, during the actual continuous casting process [11].

\subsection{Cooling, Solidification and Deformation of Steel During Continuous Casting}

The main concept of Mauder's et al. work [12] is to utilize advanced numerical modelling techniques with a self-regulation algorithm in order to reach optimal casting conditions for real-time casting control. A fully 3-D macro-solidification model for the continuous casting (CC) process and an original fuzzy logic regulator are combined. The fuzzy logic (FL) regulator reacts to signals from two data inputs, the temperature field and the historical steel quality database. FL adjusts the cooling intensity as a function of casting speed and pouring temperature. This approach was originally designed for the special high-quality high-additive steel grades such as higher strength grades, steel for acidic environments, steel for the offshore technology and so forth. However, the mentioned approach can also be used for any arbitrary low-carbon steel grades. The usability and results of this approach are demonstrated for steel grade S355, were the real historical data from the quality database contains approximately 2000 heats. The presented original solution, together with the large steel quality databases, can be used as an independent CC prediction control system [12].

Cooling rate effect on formation of non-metallic inclusions in X80 pipeline steel is the topic of the research presented by Zhang et al. [13]. Non-metallic inclusions have a strong influence on the 
hydrogen-induced cracking (HIC) and sulfide stress cracking (SSC) in pipeline steels, which should be well controlled to improve the steel resistance to HIC and SSC. The effects of cooling rate on the formation of non-metallic inclusions have been studied both experimentally and thermodynamically. It was found that the increasing cooling rate increased the number density and decreased the size of the inclusions, while the inverse results were obtained by decreasing the cooling rate. Furthermore, as the cooling rate decreased from 10 to $0.035 \mathrm{~K} / \mathrm{s}$, the inclusions were changed from $\mathrm{Al}_{2} \mathrm{O}_{3}-\mathrm{CaO}$ to $\mathrm{Al}_{2} \mathrm{O}_{3}-\mathrm{CaO}-\mathrm{MgO}-\mathrm{CaS}$. At a high cooling rate, the reaction time is short and the inclusions cannot be completely transformed, which should be mainly formed at high temperatures. Meanwhile, at a low cooling rate, the inclusions can be gradually transformed and tend to follow the equilibrium compositions [13].

Han et al. [14] reported results from the comparison of different secondary cooling strategies from the viewpoint of heat transfer and the solidification structure of billets. Water flux distribution largely influences the heat transfer and solidification of continuously cast steel billets. In this paper, a secondary cooling strategy of transverse non-uniform water flux (i.e., higher flux density on billet center), was established and compared with the uniform cooling strategy using mathematical modelling. Specifically, a heat transfer model and a cellular automaton finite element coupling model were established to simulate the continuous casting of the C80D steel billet. The water flux was measured using different nozzle configurations to assist the modelling. The mathematical results were validated by comparing the surface temperature and the solidification structure. It is shown that the non-uniform cooling strategy enables the increase of corner temperature and reduction in surface temperature difference, while a higher reheating rate is found on the surface center of the billet. Moreover, the non-uniform cooling strategy can enhance the cooling effect and refine the solidification structure. Accordingly, the liquid pool length is shortened, and the equiaxed crystal density is increased along with the decreased equiaxed crystal ratio. The uniform cooling strategy contributes to reducing internal cracks of billet, and the non-uniform one is beneficial for surface quality and central segregation. For C80D steel, the non-uniform cooling strategy outperforms the uniform one [14].

Based on all of the presented research areas, heavy reduction and its deformation behavior of internal porosity, investigated by Wu et al. [15], should be mentioned as the last but also most valuable topic included in our Special Issue. Heavy reduction (HR) is a novel technology that could effectively improve the internal porosities and other internal quality problems in continuously cast steel, during which a large reduction deformation is implemented at and after the strand solidification end. In the present paper, non-uniform solidification of the wide-thick slab was calculated with a two-dimensional (2D) heat transfer model. Based on the predicted temperature distribution at the solidification end of the casting strand, a three-dimensional (3D) thermal-mechanical coupled model was developed for investigating the deformation behavior of the internal porosities in a wide-thick slab during HR. An Arrhenius-type constitutive model for the studied steel grade was derived based on the measured true stress-strain with single-pass thermo-simulation compression experiments and applied to the 3D thermal-mechanical coupled model for improving the calculation accuracy. With the developed 3D thermal-mechanical coupled model, deformation behavior of the two artificial porosities located at the slab center of $1 / 2$ width and $1 / 8$ width during $H R$ was investigated under different conditions of $\mathrm{HR}$ deformation, HR start position, and HR reduction mode. Based on the calculated porosity closure degree $\left(\eta_{\mathrm{s}}\right)$, and the corresponding equivalent strain $\left(\varepsilon_{\mathrm{eq}}\right)$, under different HR conditions, a prediction model that describes the quantitative relationship between $\eta_{\mathrm{s}}$ and $\varepsilon_{\text {eq }}$ was derived for directly and accurately evaluating the process effect of $\mathrm{HR}$ on improving the internal porosities in a wide-thick slab [15].

\section{Conclusions}

The Special Issue, "Refining and Casting of Steel" and its research articles represent interesting examples from the most crucial challenges for maximizing the productivity and quality of continuously cast steel grades. The guest editors suppose that these papers should be inspiring for the scholars, 
researchers and technologists who are actively involved in this field. We hope that the presented articles will help them during new research studies, debates, and discussions.

Acknowledgments: The guest editors would like to thank all who contributed directly and indirectly to the successful development of this Special Issue. The guest editors thank all the scholars and authors who submitted their manuscripts and were willing to publish their research activities in this Special issue. Special mention and sincere thanks to the reviewers who agreed to review the articles and provide feedback to improve the quality of the manuscripts. Credits should also be given to the editors and to Managing Editor Natalie Sun and also all the staff of the Metals Editorial Office for their contribution and support in the publication process of this issue.

Conflicts of Interest: The authors declare no conflict of interest.

\section{References}

1. Baricová, D.; Pribulová, A.; Futáš, P.; Bul'ko, B.; Demeter, P. Change of the Chemical and Mineralogical Composition of the Slag during Oxygen Blowing in the Oxygen Converter Process. Metals 2018, 8, 844. [CrossRef]

2. Assis, A.N.; Tayeb, M.A.; Sridhar, S.; Fruehan, R.J. Phosphorus Equilibrium Between Liquid Iron and $\mathrm{CaO}-\mathrm{SiO}_{2}-\mathrm{MgO}-\mathrm{Al} 2 \mathrm{O}_{3}-\mathrm{FeO}-\mathrm{P}_{2} \mathrm{O}_{5}$ Slags: EAF Slags, the Effect of Alumina and New Correlation. Metals 2019, 9, 116. [CrossRef]

3. Calderón-Hurtado, F.A.; Dávila, R.M.; Chattopadhyay, K.; García-Hernández, S. Fluid Flow Turbulence in the Proximities of the Metal-Slag Interface in Ladle Stirring Operations. Metals 2019, 9, 192. [CrossRef]

4. Li, Y.; Zhang, T.; Duan, H. Influence of Al on Evolution of the Inclusions in Ti-Bearing Steel with Ca Treatment. Metals 2019, 9, 104. [CrossRef]

5. Zhang, K.; Cui, H.; Wang, R.; Liu, Y. Mixing Phenomenon and Flux Field in Ladle of RH Process. Metals 2019, 9, 886. [CrossRef]

6. Bul'ko, B.; Priesol, I.; Demeter, P.; Gašparovič, P.; Baricová, D.; Hrubovčáková, M. Geometric Modification of the Tundish Impact Point. Metals 2018, 8, 944. [CrossRef]

7. Bul'ko, B.; Molnár, M.; Demeter, P.; Baricová, D.; Pribulová, A.; Futáš, P. Study of the Influence of Intermix Conditions of Steel Cleanliness. Metals 2018, 8, 852. [CrossRef]

8. Wang, F.; Liu, D.; Liu, W.; Yang, S.; Li, J. Reoxidation of Al-Killed Steel by $\mathrm{Cr}_{2} \mathrm{O}_{3}$ from Tundish Cover Flux. Metals 2019, 9, 554. [CrossRef]

9. Ni, P.; Ersson, M.; Jonsson, L.T.I.; Zhang, T.A.; Jönsson, P.G. Effect of Immersion Depth of a Swirling Flow Tundish SEN on Multiphase Flow and Heat Transfer in Mold. Metals 2018, 8, 910. [CrossRef]

10. Li, Y.; Zhang, T.; Liu, C.; Jiang, M. Thermodynamic and Experimental Studies on Al Addition of 253MA Steel. Metals 2019, 9, 433. [CrossRef]

11. Zhang, K.; Liu, J.; Cui, H. Investigation on the Slag-Steel Reaction of Mold Fluxes Used for Casting Al-TRIP Steel. Metals 2019, 9, 398. [CrossRef]

12. Mauder, T.; Stetina, J. High Quality Steel Casting by Using Advanced Mathematical Methods. Metals 2018, 8, 1019. [CrossRef]

13. Zhang, X.; Yang, W.; Xu, H.; Zhang, L. Effect of Cooling Rate on the Formation of Nonmetallic Inclusions in X80 Pipeline Steel. Metals 2019, 9, 392. [CrossRef]

14. Han, Y.; Wang, X.; Zhang, J.; Zeng, F.; Chen, J.; Guan, M.; Liu, Q. Comparison of Transverse Uniform and Non-Uniform Secondary Cooling Strategies on Heat Transfer and Solidification Structure of Continuous-Casting Billet. Metals 2019, 9, 543. [CrossRef]

15. Wu, C.; Ji, C.; Zhu, M. Deformation Behavior of Internal Porosity in Continuous Casting Wide-Thick Slab during Heavy Reduction. Metals 2019, 9, 128. [CrossRef]

(C) 2020 by the authors. Licensee MDPI, Basel, Switzerland. This article is an open access article distributed under the terms and conditions of the Creative Commons Attribution (CC BY) license (http://creativecommons.org/licenses/by/4.0/). 